\title{
Learning Competent Fathering: A Longitudinal Analysis of Marital Intimacy and Fathering
}

Kay Bradford

University of Kentucky

Alan J. Hawkins

Brigham Young University - Provo, hawkinsa@byu.edu

Follow this and additional works at: https://scholarsarchive.byu.edu/facpub

Part of the Other Social and Behavioral Sciences Commons

\section{Original Publication Citation}

Bradford, K. P., \& Hawkins, A. J. (2006). Learning competent fathering: A longitudinal analysis of marital intimacy and fathering. Fathering: A Journal of Theory, Research, and Practice About Men As Fathers, 4(3), 215-234.

\section{BYU ScholarsArchive Citation}

Bradford, Kay and Hawkins, Alan J., "Learning Competent Fathering: A Longitudinal Analysis of Marital Intimacy and Fathering" (2006). Faculty Publications. 4222.

https://scholarsarchive.byu.edu/facpub/4222

This Peer-Reviewed Article is brought to you for free and open access by BYU ScholarsArchive. It has been accepted for inclusion in Faculty Publications by an authorized administrator of BYU ScholarsArchive. For more information, please contact ellen_amatangelo@byu.edu. 


\title{
Learning Competent Fathering: A Longitudinal Analysis of Marital Intimacy and Fathering
}

\author{
KAY BRADFORD \\ University of Kentucky
}

\author{
Alan J. Hawkins \\ Brigham Young University
}

\begin{abstract}
Although scholars have documented many links between marital relationships and parenting, these associations are not commonly explained in terms of behavior that is learned or achieved over time. This paper examines the idea that good fathering - conceptualized here as competent fathering - is the result of a developmental process, and that a loving, committed relationship between parents creates a context in which traits supportive of caring fathering are likely to be learned and practiced. After setting the stage conceptually, we provide a modest initial test of this hypothesis to discern the associations between three components of marital intimacy (emotional intimacy, commitment, and passion) and fathering. Results yielded positive, moderate concurrent associations between marital intimacy and fathering, and positive, low associations between these variables longitudinally. These associations give a degree of support to the notion of fathering as a developmental process, and confirm the sensitivity of fathering to the marital context.
\end{abstract}

Keywords: fathering, marital intimacy, parenting

The reciprocal impact of marital processes on parenting and on child well-being are increasingly recognized and studied (e.g., Fincham, 1998; Harold, Fincham, Osborne, \& Conger, 1997). However, the potentially cumulative impact of these domains upon one another tends to be considered less frequently. That is, marriage and parenting are not typically viewed as developmentally linked to each other (Dollahite \& Hawkins, 1998; Hawkins, Christiansen, Sargent, \& Hill, 1993; Snarey, 1993). We examine parenting, and fathering in particular, in terms of behavior that is learned or achieved.

The purpose of this paper is to clarify how marital relationships precede and support competent fathering. The two goals of this paper are: (1) to develop the term "competent fathering" as a larger concept that subsumes the traditional notion of father

Kay Bradford, Department of Family Studies, University of Kentucky; Alan J. Hawkins, School of Family Life, Brigham Young University.

Correspondence concerning this article should be sent to Kay Bradford, Department of Family Studies, University of Kentucky, 319A Funkhouser, Lexington, KY 40506. Electronic mail: kbrad@uky.edu

Fathering, Vol. 4, No. 3, Fall 2006, 215-234.

(C) 2006 by the Men's Studies Press, LLC. http://www.mensstudies.com. All rights reserved.

$1537-6680.04 .215$ 
involvement, and (2) to test the idea that marriage and fathering are linked by learning processes that establish caring qualities in both roles.

The Role of Intimacy in the Development of Competent Fathering

Development is characterized by a move from less differentiation to greater differentiation, and often consists of both qualitative and quantitative changes (Lerner, 1986). A developmental view of parenthood involves change in a person's sense of self - that is, who a person is, and who she or he will be (Cowan, 1991). Thus, rather than examining fathers' skills, we give attention to interpersonal processes that facilitate the development of qualities of good fathering. The concept tested in this study is the idea that an intimate, committed marital relationship helps create a foundation for competent, caring fathering. We test the idea that competent fathering rests on the development of interpersonal learning experiences across the lifespan, and particularly upon the experiences found in what Erikson (1964) labeled the intimacy stage of life. Many studies suggest that the most immediate developmental influence on parenting is an intimate relationship both prior to and concurrent with parenthood (Cummings \& O'Reilly, 1997; Erel \& Burman, 1995). That is, a loving, committed relationship creates a context in which traits of caring parenting are likely to be learned and practiced. If this hypothesis is accurate, higher levels of marital intimacy (measured here as emotional intimacy, commitment, and passion) should predict competent fathering both longitudinally and concurrently.

More common, however, is a "structural" perspective of fathering. In this view, the institution of marriage normatively connects children to fathers through proximity, which ostensibly increases involvement (Nock, 1998). Marriage in North America often provides the foundation upon which families are formed (Hetherington \& Parke, 1993; Whyte, 1990), and by which children are protected and nurtured (Doherty, Kouneski, \& Erikson, 1998), although this may be less normative than in past decades (Teachman, Tedrow, \& Crowder, 2000). Conversely, our proposed developmental perspective on fathering suggests that without prior experiences that help teach, develop, and maintain relational intimacy, both mothers and fathers may struggle in caring for their children (Snarey, 1993). Obviously, the connection between intimacy and fathering does not represent a universal pathway that applies to everyone because the courses of development found in human experience are vast. We limit the present study to married couples, but this does not suggest that learning processes do not occur in relationships outside of traditional marriage. Rather, our goal in this study is to test elements of adult development that, while not universal, may constitute a developmental course that is typical for many.

In addition to our focus on marriage, we also focus on fathering and its sensitivity to the context of intimate relationships (Doherty et al., 1998; Erel \& Burman, 1995; McBride \& Rane, 1998). Comparatively, father-child relationships are more affected by the parental alliance between a couple (McBride \& Rane, 1998), marital conflict (Krishnakumar \& Buehler, 2000), and low marital satisfaction than are mother-child relations (Cummings \& O’ Reilly, 1997). 


\section{Past and Present Views on Father Involvement}

Scholarship on fathering activities has typically used the term "father involvement." In the mid-twentieth century, research on fathers had often been approached from a "father absence" point of view, which to a great extent was a content-free notion of father involvement (Pleck, 1997). In recent years, however, this term has been criticized for failing to capture important aspects of fathering, such as a father's cognitions regarding his child(ren), effect on the parent-child relationship, work inside and outside the home, and support of the mother's role (Hawkins \& Palkovitz, 1999; Palkovitz, 1997; Pleck \& Stueve, 2001). Furthermore, the focus on involvement is inadequate because it is non-developmental and does not comprise response to the changes in children as they develop and mature (Hawkins \& Dollahite, 1997). More broadly, scholarship on fathering has been criticized for lacking theoretical underpinnings, resulting in limited ability to conceptualize and measure fathering with adequate depth and breadth (Snarey, 1997). We propose "competent fathering" as a term that describes affective and cognitive aspects of fathering as well as behavioral aspects. The notion of competent fathering is also at least somewhat developmental, because it implies that fathering is comprised of abilities, skills, and even identities that may be developed over time.

Over two decades ago, Belsky, Robins, and Gamble (1984) defined good versus poor parenting, noting that the definitions had been left implicit. Parental competence was defined as having two components: sensitivity and involvement. That is, the parent must be sensitive to the child's needs in developmentally appropriate ways, but this sensitivity must be put into action if the caregiver is to be considered competent. In addition, Belsky et al. (1984) delineated three determinants of sensitivity and involvement-patience, endurance, and commitment-and noted that these three determinants have reciprocal influence on each other. Sensitivity includes allocentrism (other-centeredness), empathy, developmental understanding, and even personal characteristics as personal resources for good parenting. We use the concept of parental competence as a foundation upon which to integrate the conceptual work that followed.

In recent years, father involvement has been seen as a composite of caring activities that includes a range of cognitive, affective, and behavioral components. Notable contributions include Lamb and colleagues' conceptualization of paternal involvement as having the three major components of engagement, accessibility, and responsibility (Lamb, Pleck, Charnov, \& Levine; 1985, 1987); Palkovitz's (1997) multi-faceted description of father involvement as a response to the affective, behavioral, and cognitive developmental needs of others in the family; Dollahite and Hawkins' (1998) description of fathering as work that responds to the needs of the next generation; and Marsiglio, Day, and Lamb's (2000) social constructivist perspective of paternal influence, comprised of nurturance and care, moral and ethical guidance, emotional, practical, and psychosocial support of female partners, and economic provisioning.

Despite recent conceptual advances, the label of "father involvement" itself remains primarily a behavioral construct. Indeed, Pleck (1997) asserted that the concept of father involvement was never intended to encompass all the important aspects of fa- 
thering. Moreover, "father involvement" is only one of several modes of paternal influence on child development (Lamb et al., 1987). Conversely, the notion of father competence comprises affective, behavioral, and cognitive aspects of fathering, including father involvement, father identity, parental satisfaction, and generativity. Father involvement includes components as diverse as traditional notions of behavioral involvement, breadwinning, systemic involvement (e.g., the co-parental relationship), and psychological and affective involvement. Paternal identity refers to the ways in which one's identity shapes behavior, particularly as that identity is reflected from significant others (Maurer, Pleck, \& Rane, 2001). Identity is thus a mechanism of parental sensitivity, because of its influence on fathers' behavior (Belsky et al., 1984). Satisfaction in fathering is one manifestation of the growth of self that can occur in the process of fathering. Satisfaction is, in part, the operation of positive (or negative) feedback inherent to fathering. Fathering has impact on the well-being of the caregiver, not just on the recipient of care (Hawkins, Christiansen, Sargent, \& Hill, 1993). Generativity is connected to the theoretical writings of Erik Erikson (1964) and is defined as caring for the next generation. Generativity is a developmental stage in which one's point of reference moves beyond one's self toward a larger scope of care, and includes concern for the contexts in which children live.

\section{Marriage as an Antecedent to Fathering}

To understand how marriage can lay a foundation for competent fathering, it is necessary to understand the nature of mature intimacy. Sternberg's (1986) triangular theory of love suggests that love is comprised of three components: intimacy, commitment, and passion. Subsequent studies have confirmed these three components (Barnes \& Sternberg, 1997; Fehr, 1993). The process of learning and developing these three components may provide important experiences that will help build and sustain caring, committed parenthood. The process of relational learning posited here may also be linked to romantic attachment. Attachment styles in infant-caregiver relationships resemble those observed in romantic relationships. Moreover, adult attachment reflects the beliefs that people have about themselves and their close relationships (Fraley \& Shaver, 2000).

It may be that demographic trends such as delayed marriage, cohabitation, and remarriage would bring considerable variation to this process. Whether the process itself remains relatively constant in such contexts is a question for future study. We now cite empirical evidence that links intimacy's three components with parenting and discuss the connections between intimacy and fatherhood.

\section{Learning Emotional Intimacy}

Learning processes in interpersonal relationships form an important foundation for the ability to care for others (Bukowski, Newcomb, \& Hartup, 1996). Through a process of interactions and accompanying cognitions, individuals develop schemata, 
which are knowledge structures based on prior experience (Andersen, 1993). Schemata give meaning to later interactions, and thus help define an individual's prototype (i.e., one's own subjective notion) of what it means to be a brother, a friend, or a mother or a father. This type of knowledge is similar to the concept of "working models" in attachment theory.

Romantic experiences in adolescence may play an important part in the development of identity. Buhrmester's (1996) aggregated data show that intimate disclosures to peers are more frequent during adolescence than they are to romantic partners, but by late adolescence, intimate disclosures to romantic partners exceed disclosures to peers. This pattern becomes increasingly prevalent as the individual approaches marriage (Buhrmester, 1996). Hence, early romantic relationships may help adolescent boys begin to look toward long-term romantic relationships. Although romantic intimacy is qualitatively different from intimacy in the parent-child relationship, there are shared components, such as reciprocity and disclosure (Fehr, 1993). Moreover, in North American society, marriage is often linked with fatherhood (Nock, 1998).

The links between couple dynamics and parenting suggest that these learning processes spill over into parent-child relationships. Evidence suggests that good marital relationships benefit children and parent-child relationships both prior to parenthood and concurrent with it (Erel \& Burman, 1995). Some of the strongest evidence comes from the literature on attachment. For example, Howes and Markman (1989) found that the quality of a couple's relationship before marriage as well as after their child is born is related to child attachment and security. Similarly, a longitudinal study found that positive marital engagement was significantly associated with more secure fatherchild attachment in fathers of three-year-olds while marital conflict was negatively associated with security (Frosch, Mangelsdorf, \& McHale, 2000). Related to these findings, another study found that parents with high scores on attachment avoidance were less responsive when their children were distressed (Edelstein et al., 2004). Child attachment even has an impact on children's view of their parents' relationships. Davies and Forman (2002) found that securely attached children displayed well-regulated concern and positive representations of the interparental relationship; insecure-preoccupied children, as well as insecure-dismissing children, demonstrated relatively high distress, involvement, and negative representations of interparental relationships. Taken together, these studies suggest that co-parenting processes and marital interactions are reciprocally related over time.

Marital intimacy is also linked to positive parent-child relationships concurrently (e.g., Belsky \& Hsieh, 1998; Shek, 1998). Mother-child and father-child relations are more positive in harmonious marriages (see Cummings \& O' Reilly, 1997), and parents in satisfying marriages give more favorable ratings of both their children and the parenting role (Goldberg, 1990). In one study, fathers who reported higher marital satisfaction displayed less negative behavior and more sensitive behavior in interactions with their children (Belsky, Youngblade, Rovine, \& Volling, 1991). In another, it was found that fathers have more positive attitudes toward their infants and their roles as fathers when they rate their marriages as close and confiding (Cox, Owen, Lewis, \& Hen- 
derson, 1989). Conversely, parental attachment insecurity is associated with ambivalence about parenthood and more negative models of parenthood (Rholes, Simpson, Blakely, Lanigan, \& Allen, 1997). Fathers tend to distance themselves from their children when marital relations deteriorate (Cummings \& O' Reilly, 1997).

Further research indicates that positive marital interactions support positive coparenting (Belsky \& Hsieh, 1998), and that the parenting alliance is positively linked to paternal involvement (McBride \& Rane, 1998). One study found that couples whose initially good marital quality deteriorated over a two-year period engaged in unsupportive co-parenting significantly more often compared to couples whose relationships went from bad to worse and couples whose relationships stayed good (Belsky \& Hsieh, 1998). Thus, a couple's interdependence in marriage and co-parenting seems to impact the quality of parent-child relationships. Salient elements include effective communication, problem-solving skills, emotional involvement, and support.

\section{Learning Commitment}

In Sternberg's (1986) theory, commitment refers to devotion to a specific person, and to the decision that is made to remain in love and remain in the relationship over a long period of time (Sternberg, 1986). Snarey (1993) found that fathers' commitments to their marriages were a strong predictor of later paternal generativity, particularly with daughters. Thus, the development of commitment in intimacy may provide a foundation for commitment in fatherhood. In North America, marriage may often be the first long-term commitment one makes due to the cultural emphasis on self. Learning the value of commitment and how to commit and sacrifice in a relationship that is built on reciprocal care (i.e., in mature intimacy) may provide an important foundation for commitment in a relationship that is decidedly more one-sided (i.e., in parenting).

Part of commitment in a loving relationship is a determination to make the relationship as mutually satisfying as possible (Noller, 1996). This is part of what Stanley, Whitton, and Markman (2004) label "personal dedication." Differentiated from duty to the relationship out of obligation, personal dedication is characterized by "other-centeredness," development of a couple identity (or sense of "we-ness"), and putting a high priority on the relationship (Stanley et al.). Personal dedication also includes sensitivity to and allocentric perspective of one's partner (i.e., with interest centered in one's partner versus one's self) over the long term. The achievement of such commitment could form a foundation on which to expand one's circle of care to the next generation.

\section{Learning Passion}

Passion includes romantic and sexual aspects of loving relationships (Sternberg, 1986), and is a way of feeling, thinking, and acting toward another centered in a profound desire to be with another. Passion is the most obvious connection between intimacy and what Kotre (1984) describes as biological generativity-the conception, 
bearing, and initial care of children. Existing support for this link is limited. However, one longitudinal study found a positive association between frequency and pleasure of marital sex and later paternal competence (Heath, 1976). It is possible that lasting passion may be one aspect of the enduring strength that defines and holds together families.

Taken together, the evidence cited above supports the conclusion that relationship processes shape the development of nurturing capacities, and thus have impact on parent-child relationships. Limited experiences with mature emotional intimacy likely hinders one's development of warmth, empathy, and competence as a parent. Without experiencing commitment in a loving relationship, one is less likely to value permanence and devotion to an intimate other, and thus, less likely to bring a sense of commitment to the parent-child relationship. Similarly, without experiencing enduring passion, one may be less likely to seek the enjoyment often integral to parent-child relationships

\section{Overview of the Study}

As a modest step toward exploring father competence as a developmental process, we tested the associations between martial intimacy (i.e., emotional intimacy, commitment, and passion) and fathering. We hypothesized that the three components of intimacy at Time I would be positively associated with fathering activities (Time II), and that the three components of intimacy at Time II would also be positively associated with fathering activities (Time II). Although this test is simple relative to the complexity of the hypothesis, it seemed a logical first step to test these links. Later research on the process of relational learning might include gathering data at multiple points of time to better assess which aspects of intimacy are associated with particular aspects of fathering at various points in time. Moreover, diversity in family formation and other demographic variation such as age, as well as issues related to divorce and remarriage (Pill, 1990), may lend further complexity to the process and could be addressed in future studies.

\section{Method}

\section{Participants}

This study was conducted using data initially collected by the Marriage Study Consortium at Brigham Young University, with Time II data subsequently collected independently. Participants recruited for this study included couples who had previously completed the RELATE relationship evaluation instrument (Holman, Busby, Doxey, Klein, \& Loyer-Carlson, 1997). Participants selected for inclusion in the second data collection point were couples who had children at the time of follow-up. Approximately 180 surveys were sent via U.S. post, and the response rate was approximately 48.8 percent $(N=88)$. There were no significant differences between those who responded versus those who did not regarding income, education, and religious affiliation. No 
compensation was offered for participation.

Data for this study were collected from a small, non-probability sample with measures designed specifically to capture the theoretical complexities of father competence. Table 1 provides descriptive statistics of the sample. Data were collected between January, 1997 and August, 1998 (Time I). Follow-up survey data were collected between November, 2000 and January, 2001. Unfortunately, measures of fathering were not taken during Time I data collection. We were thus unable to assess changes in fathering measures over time.

Table 1

Descriptive Sample Data

\begin{tabular}{|c|c|c|}
\hline & Fathers & Mothers \\
\hline$N$ & 44 & 44 \\
\hline Age, $M$ & 34 & 33 \\
\hline \multicolumn{3}{|c|}{ Number of times married } \\
\hline 1 & $38(87 \%)$ & $38(87 \%)$ \\
\hline 2 or more & $6(13 \%)$ & $6(13 \%)$ \\
\hline \multicolumn{3}{|l|}{ Ethnicity } \\
\hline \multicolumn{3}{|c|}{ African-American } \\
\hline Hispanic & & $1(2 \%)$ \\
\hline Caucasian & $44(100 \%)$ & $42(96 \%)$ \\
\hline Other & & $1(2 \%)$ \\
\hline \multicolumn{3}{|c|}{ Religious preference } \\
\hline LDS & $43(98 \%)$ & $43(98 \%)$ \\
\hline No preference & $1(2 \%)$ & $1(2 \%)$ \\
\hline \multicolumn{3}{|l|}{ Children } \\
\hline Modal number & \multicolumn{2}{|c|}{3} \\
\hline Age range & \multicolumn{2}{|c|}{ 1-17 yrs. } \\
\hline Age, $M$ & \multicolumn{2}{|c|}{8 yrs. } \\
\hline
\end{tabular}

Education

11 years or less

High School

Some College $\quad 8(18 \%) \quad 9(20 \%)$

4-yr degree $\quad 14(32 \%) \quad 28(64 \%)$

GraduateWork/degree $22(50 \%) \quad 7(16 \%)$

$\begin{array}{cll}\text { Employed } & 44(100 \%) & 16(36 \%) \\ \text { Mean hrs worked / wk. } & 43 & 16\end{array}$

Family Income, $M$ 


\section{Measures and Procedures}

Intimacy. Emotional intimacy at Time I and at Time II was measured using 10 items selected from the RELATE relationship evaluation (Holman et al., 1997). RELATE is a 271-item, self-report instrument designed to help individuals and couples evaluate the quality of a current premarital or marital relationship. Both husbands and wives responded on a five-point Likert scale to reflect their level of satisfaction with intimacy in their relationships. Sample items include "I include my (spouse) in my life," "How often have you thought your marriage might be in trouble?", and "the physical intimacy you experience."

Due to the co-constructed nature of intimacy, we conducted factor analysis on responses from both husbands and wives to create multiple-perspective measures. There is evidence that youth and child reports of their parents' relationship provide stronger effects on parenting behaviors than when reported by mothers or fathers (Krishnakumar $\&$ Buehler, 2000). This finding suggests that the holistic impact of the couple relationship (and thus a co-constructed measure) may be most salient to a family process model. Based on Sternberg's (1986) triangular theory of intimacy, we theorized that these items would form three components of intimacy: emotional intimacy, commitment, and passion. To test this theory, we selected 14 RELATE items based upon the face validity of each item as it related to the three components of Sternberg's theory of intimacy. We performed exploratory factor analyses for both Time I and Time II data. Ten of the original 14 items had acceptable factor loadings and reliability levels. Emotional intimacy is an aggregate of 5 items from each spouse; factor loadings for Times I and II ranged from .60 to .88 , explained 58 percent of the variance (at each time), and the Cronbach's alpha level for emotional intimacy at both Time I and Time II was .92 . Commitment is an aggregate of 2 items from each spouse; factor loadings for Times I and II ranged from .74 to .86 , explained 71 percent and 57 percent of the variance (respectively for Times I and II), and the alpha levels for commitment at Times I and II were .85 and .75. Passion is an aggregate of 3 items from each spouse; factor loadings for Times I and II ranged from .60 to .88 , explained 48 percent and 56 percent of the variance, and the alpha levels for passion at Times I and II were .83 and .86 , respectively. The above procedures resulted in 10 manifest variables that were then included in the structural model as observed variables.

Competent fathering. The measure of competent fathering include 10 items from the 26-item Inventory of Father Involvement (Hawkins et al., 2002), with items such as "How would you describe your (or your husband's) involvement in praising your children for being good or doing the right thing," "providing for your children's basic needs," and "giving your children's mother encouragement and emotional support." The ten items selected were chosen because they are most appropriate for children whose developmental stages span from early school-age to late adolescence. The responses ranged from $1=$ poor to 7 = practically perfect . Fathers' assessments of role identity were measured with 4 items from the 11-item Caregiving Identity Scale of the 
Caregiving and Breadwinning Identity and Reflected-Appraisal Inventory (Maurer, Pleck, \& Rane, 2001). Sample items include "It is important to me to be a good caregiver to my child" and "If my wife wanted to do all the caregiving by herself, that would be ok with me." The responses ranged from $1=$ strongly disagree to $5=$ strongly agree. Fathers' parental satisfaction was measured with the 3-item Kansas Parental Satisfaction Scale (Schumm, 1986), with items including, "How satisfied are you with yourself as a parent?" and "How satisfied are you with your relationship with your children?" The responses ranged from $1=$ very dissatisfied to $7=$ very satisfied. Generativity was measured using 6 items from the 20-item Loyola Generativity Scale (LGS, McAdams \& de St. Aubin, 1992), with items such as, "I try to pass along the knowledge I have gained through my experiences" and "I have important skills that I try to teach others." The responses ranged from $1=$ never applies to $4=$ applies very often .

Exploratory factor analyses yielded the following: The father involvement factor loadings ranged from .63 to .87 , explained 65 percent of the variance, and the Cronbach's alpha level was .73; paternal caregiving identity factor loadings ranged from .69 to .79 , and explained 53 percent of the variance; the alpha level was .68 . The father satisfaction factor loadings ranged from .64 to .90 , explained 65 percent of the variance, and the alpha level was .82 . The generativity factor loadings ranged from .67 to .82 , explained 55 percent of the variance, and the alpha level was .82 . The resulting 4 manifest variables were then included in the structural model as observed variables.

The model examined in this study designates three latent variables: intimacy (Time I), intimacy (Time II), and father competence (Time II). As previously described, we used items from several existing instruments to capture the theoretical richness of positive father activities, including various affective, behavioral, and cognitive dimensions. Each of these three latent variables indicates its own set of manifest variables, all 10 of which were derived from the aggregated scores of individually observed items. Figure 1 presents the resulting 10 manifest variables and three latent variables that comprise this structural model.

\section{Plan of Analysis}

Partial least squares (PLS) estimation was used to test the multivariate associations between the latent variables (Falk \& Miller, 1996). Conventional maximum likelihood estimation makes restrictive assumptions regarding measurement and distribution that are difficult to achieve in social science data. We used PLS due to its mathematical rigor, but also its freedom in terms of distributional assumptions of normality. Both were of particular importance given the small sample. Figure 1 presents the structural model. Similar to conventional structural equation modeling (SEM), this technique allows the simultaneous estimation of parameters among both exogenous and endogenous variables, taking into account the other correlations (Anderson \& Gerbing, 1988). Due to its asymptotic properties, the structural paths between the latent variables tend to be underestimated, while the correlations of the latent variables to their respective ob- 


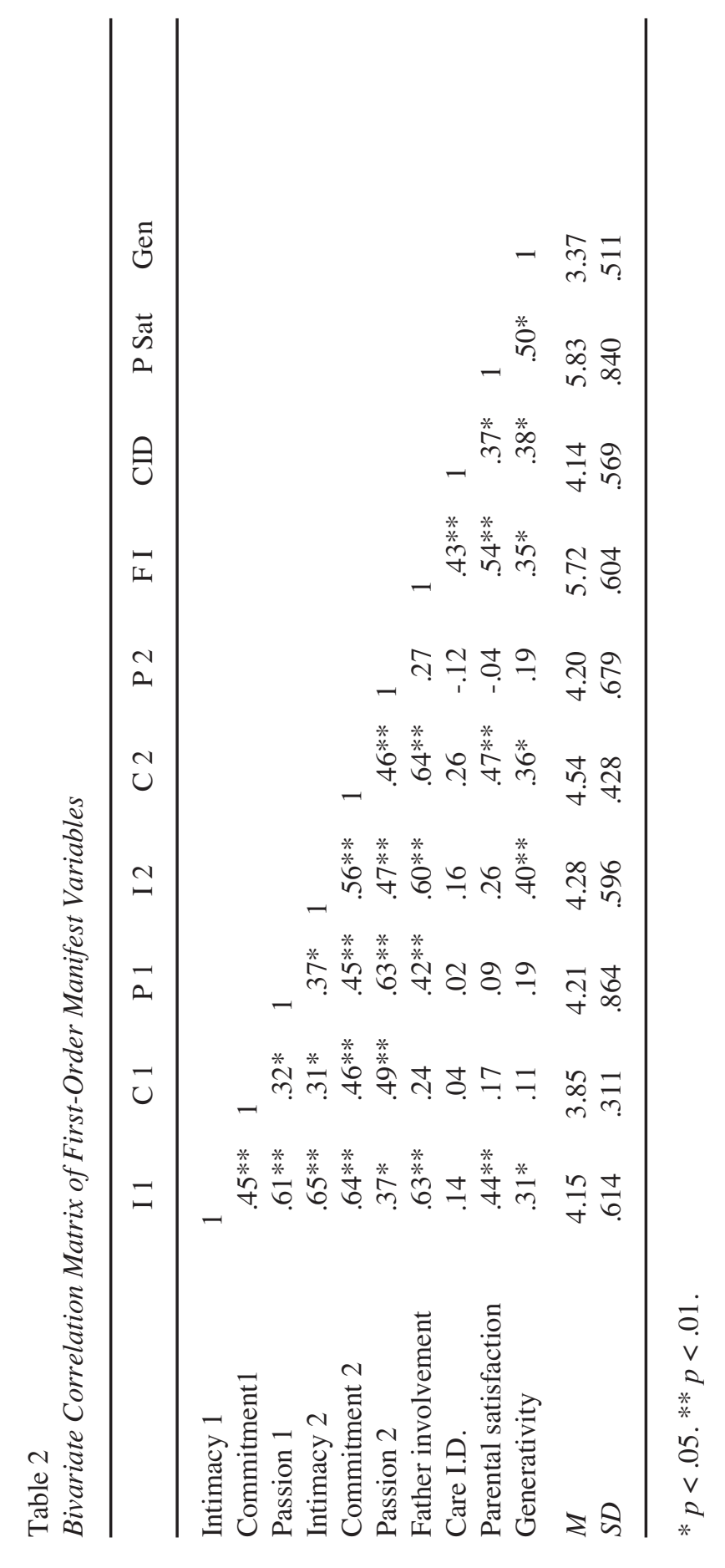




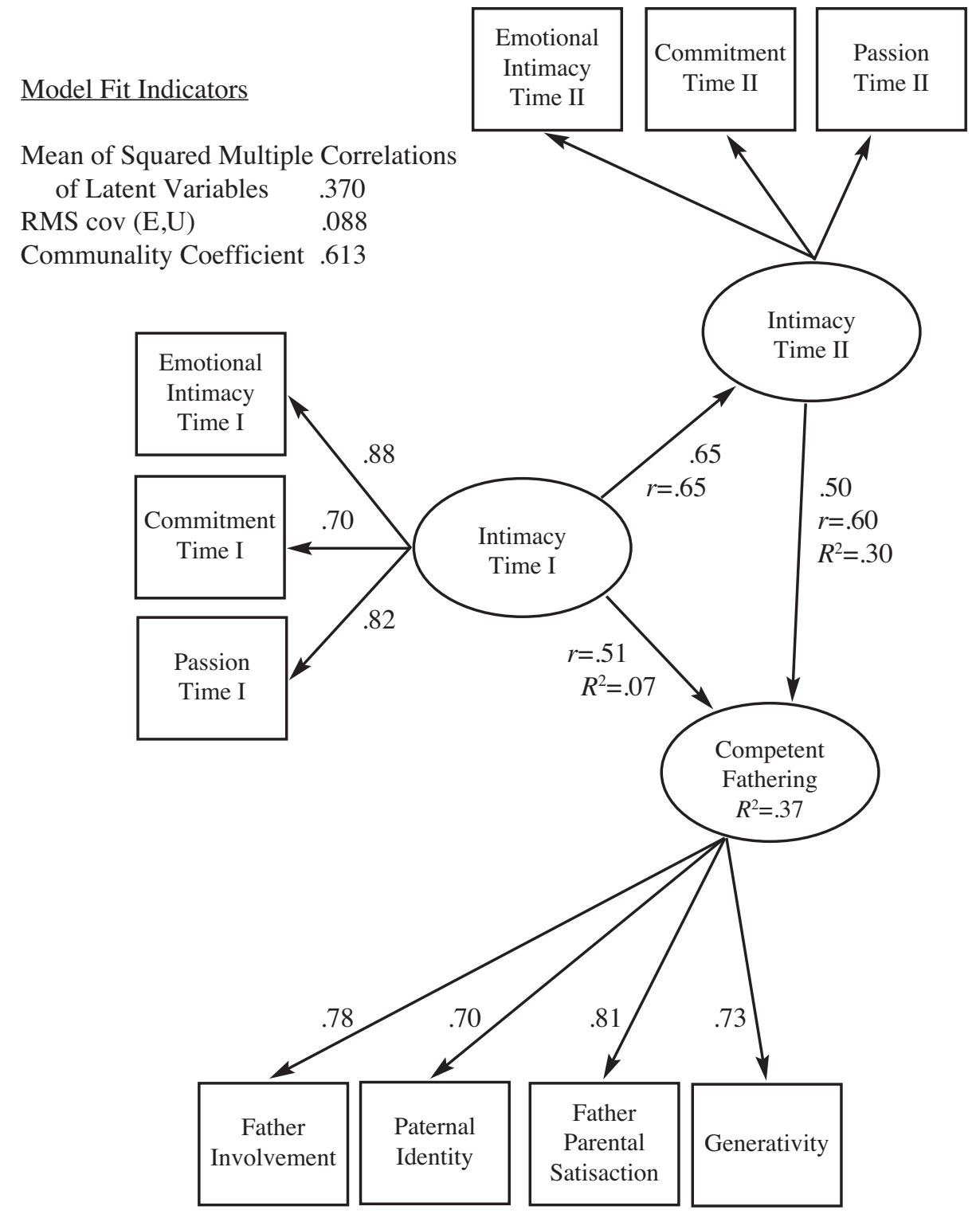

Figure 1. Path coefficients and model fit. 
served variables tend to be overestimated (Anderson \& Gerbing, 1988). There were very few missing data (i.e., between $2 \%-4 \%$ ); missing data were deleted from the analyses.

Table 2 presents the bivariate correlations between the 10 manifest variables in this partial least squares model. A test of the full model was performed using the 10 manifest variables and 3 latent constructs of interest (see Figure 1 for coefficients and overall model fit). Again, in all cases, the manifest variables all had reasonable principle component loadings and thus indicated Sternberg' s (1986) three components of intimacy at both points of measurement.

Standardized regression coefficients for the full model are presented on the appropriate paths in Figure 1. In addition, the bivariate correlations between the latent variables are presented on the appropriate paths, along with the proportion of total variance in father competence that is explained by the paths. The bivariate correlation between intimacy Time I and Time II showed stability between these measures $(r=.65)$. Intimacy at Time I was strongly correlated with father competence $(r=.51)$, but with intimacy Time II added to the model, the effect diminished markedly $(b=.14)$. Intimacy at Time II was strongly correlated with father competence $(r=.60)$, with the effect only slightly diminished in the presence of intimacy Time I in the model $(b=.50)$. Approximately 37 percent of the total variance in competent fathering is accounted for by the paths specified in the full model. Intimacy at Time I, as rated by both husbands and wives, explains approximately 7 percent of the variance, and intimacy at Time II, also rated by both husbands and wives, explains approximately 30 percent.

The model fit is related to the ability of the model to account for variance. The fit measures relate to how well the parameter estimates are able to match the covariances. The overall fit, or the communality coefficient of the model, was .622. Levels of .30 and above are considered to be acceptable (Falk \& Miller, 1996); thus the current coefficient indicates a good fit. The measure of residual error, or the root mean square of the covariance between the manifest variable residuals and the latent variable residuals (RMS Cov [E,U]) was .088. In PLS, this coefficient should be below .20 in order to be acceptable. PLS does not calculate standard errors for the specific path coefficients, and so significance tests for the effects of these paths are not available (Anderson \& Gerbing, 1988; Fauber, Forehand, Thomas, \& Wierson, 1990). However, it is generally accepted that a predictor variable should account for at least 1.5 percent of the variance in a predicted variable (Falk \& Miller, 1996). Therefore, although modest, the path between intimacy Time I and father competence should be considered significant, as it explains about 7 percent of the variance in the endogenous variable. The path between intimacy Time II and father competence was significant as it explains 30 percent of the variance in the endogenous variable.

\section{Discussion}

The goals of this study were twofold: first, to set forth a developmental explanation of the links between marital intimacy and fathering as a supplement to the common 
structural explanation, and second, to provide a modest empirical test of these links longitudinally and concurrently. We first discuss findings from the structural model, and then comment on the findings in terms of their potential for further research on fathering as a developmental process.

The basic hypothesis of the study was supported. There was a longitudinal relationship observed between intimacy Time I and competent fathering, which, although low in magnitude, was meaningful in explaining variance in the model (Falk \& Miller, 1996). In addition, intimacy was observed to be moderately associated with competent fathering concurrently. Thus, the results indicate that aspects of marital intimacy link positively to fathering activities both distally and concurrently. These findings are largely consistent with existing literature, which has documented various links between the marital relationship and parent-child relationships, both longitudinally (e.g., Belsky \& Hsieh, 1998; Booth \& Amato, 1994; Heath, 1976; Shek, 1998) and concurrently (e.g., Erel \& Burman, 1995; Fauber et al., 1990; Fincham, 1998).

Beyond extant findings, the present study points toward a developmental component in family processes. The presence of a distal association between marital intimacy and competent fathering suggests that the effects of marital process on father-child interactions endure over time. It is possible that the longitudinal association in this study manifests in part an underlying developmental process comprised of relational experiences that transfer from the marital context to the parent-child context (Fincham, 1998). It is also important to note that because family subsystems exert reciprocal influence on one another (Wood, Klebba, \& Miller, 2000), parenting also has impact on intimacy. This reciprocal process is evident particularly in the linkage between intimacy at Time 2 and fathering, which suggests that competent fathering is supportive of marital intimacy.

The connection between intimacy and fathering does not represent a universal pathway that applies to all fathers because of the great diversity of the course of human development. The present study was limited to married couples as are the findings. Further research is needed regarding the extent to which similar learning processes occur in relationships outside of traditional marriage. There are also considerable limitations in the sample due to the small sample size as well as the homogeneity of ethnicity, religion, SES, and maternal employment status. It is important to note that pathways of learning competent fathering are likely very diverse (Hetherington, Bridges, \& Insabella, 1998). However, our goal in this study was to test an element of adult development that, while not universal, may constitute an important developmental course.

Research on relationship processes supports the notion that adequate functioning in any relationship requires the competent use of knowledge across time, and that it is in the context of close relationships with family members and friends that we learn about human relationships (Barber \& Olsen, 1997; Fletcher \& Fitness, 1993). There is also research to suggest that the marital relationship is particularly important to learning (Bartholomew, 1993). This underscores the potential benefit of studying the link between marital intimacy and fathering from a developmental perspective of learned be- 
haviors. Father competence may therefore be the result of a long learning process with roots in close relationships. Given the centrality of marriage and its particular impact on father-child relationships (White, 1999), positive associations between intimacy and fathering such as those observed in this study may manifest these learning processes. One finding to support this possibility is the moderate bivariate correlation observed between fathers' caregiving identity and their ratings of father involvement $(r=.43)$. This correlation may indicate a link between fathers' cognitive definitions of their roles as fathers, and their actual activities as fathers.

The current findings, coupled with evidence from the relationship processes literature, justify further research from a developmental perspective. More precise and frequent measurement of the various components of intimacy and father competence over time may yield a clearer picture of these associations, and also yield a more nuanced picture of how marital processes positively and negatively affect parent-child relations (Buehler \& Gerard, 2002). Further research should also include the study of larger, more diverse samples.

This study serves as a preliminary step toward investigating fathering activities from a developmental perspective. Such a perspective presents challenges in measurement and research design. Diversity in family formation and other demographic variation lends further complexity to the process. Residential stepparents, for instance, often face the challenge of building new parent-child relationships while concurrently building marital intimacy (Pill, 1990). Likewise, marrying earlier or later in life may create wide variation in one's experiences with intimacy and fathering. The accessibility of marriage and cultural attitudes toward marriage and childcare are also important considerations (Morehouse, 1999). Future research might also explore potential differences in effects due to these and other demographic variations, including gender, ethnicity, sexual orientation, and cultural differences.

\section{Conclusion}

We have drawn on existing literature to conceptualize competent fathering as a construct that moves beyond involvement by embracing other important aspects of male parenting, some of which include identity, satisfaction, and generativity. Limitations notwithstanding, the current results give initial support to a developmental view of fathering as learned behavior. Such a perspective may lead to a better understanding of the mechanisms that link intimacy and fathering. It is clear that a positive and stable couple relationship creates a context in which the investments required in bearing and rearing a child may be borne jointly. In addition to its structural benefits, however, such relationships may facilitate the expansion of relationship knowledge and proficiency in parent-child relationships, thereby promoting well-being for both marital partners and for their children. Taken together, evidence suggests that as we seek to understand and promote positive relationships between fathers and children, we should attend to the intimate relationships that developmentally nurture them. 


\section{References}

Andersen, P. A. (1993). Cognitive schemata in personal relationships. In S. Duck (Ed.), Individuals in relationships (pp. 87-120). Thousand Oaks, CA: Sage.

Anderson, J. C., \& Gerbing, D. W. (1988). Structural equation modeling in practice: A review and recommended two-step approach. Psychological Bulletin, 103, 411423.

Barber, B. K., \& Olsen, J. A. (1997). Socialization in context: Connection, regulation, and autonomy in the family, school, and neighborhood, and with peers. Journal of Adolescent Research, 12, 287-315.

Barnes, M. L., \& Sternberg, R. J. (1997). A hierarchical model of love and its prediction of satisfaction in close relationships. In R. J.Sternberg \& M. Hojjat (Eds.), Satisfaction in close relationships (pp. 79-101). New York: Guilford.

Bartholomew, K. (1993). From childhood to adult relationships: Attachment theory and research. In S. Duck (Ed.), Understanding relationship processes series (Vol. 2). Learning about relationships (pp. 30-62). Thousand Oaks, CA: Sage.

Belsky, J., \& Hsieh, K. H. (1998). Pattern of marital change during the early childhood years: Parent personality, coparenting, and division-of-labor correlates. Journal of Family Psychology, 12, 511-528.

Belsky, J., Robins, E., \& Gamble, W. (1984). The determinants of parental competence: Toward a contextual theory. In M. Lewis (Ed.), Beyond the dyad (pp. 251-279). New York: Plenum Press.

Belsky, J., Youngblade, L., Rovine, M., \& Volling, B. (1991). Patterns of marital change and parent-child interaction. Journal of Marriage and the Family, 53, 487498.

Booth, A., \& Amato, P. R. (1994). Parental marital quality, parental divorce, and relations with parents. Journal of Marriage and the Family, 56, 21-34.

Buehler, C., \& Gerard, J. M. (2002). Marital conflict, ineffective parenting, and children's and adolescents' maladjustment. Journal of Marriage and the Family, 64, 78-92.

Buhrmester, D. (1996). Need fulfillment, interpersonal competence, and the developmental contexts of early adolescent friendship. In W. M. Bukowski, A. F. Newcomb, \& W. W. Hartup, (Eds.), The company they keep: Friendship in childhood and adolescence (pp 158-185). Cambridge, MA: Cambridge University Press.

Bukowski, W. M, Newcomb, A. F., \& Hartup, W. W.(1996). Friendship and its significance in childhood and adolescence: Introduction and comment. In W. M. Bukowski, A. F. Newcomb, \& W. W. Hartup, (Eds.), The company they keep: Friendship in childhood and adolescence (pp 1-18). Cambridge, MA: Cambridge University Press.

Cowan, P. A. (1991). Individual and family life transitions: A proposal for a new definition. In P. A. Cowan \& M. Hetherington (Eds.), Family transitions (pp 3-30). Hillsdale, NJ: Lawrence Erlbaum. 
Cox, M. J., Owen, M. T., Lewis, J. M., \& Henderson, V. K. (1989). Marriage, adult adjustment, and early parenting. Child Development, 60, 1015-1024.

Cummings, E. M., \& O'Reilly, A. W. (1997). Fathers in family context: Effects of marital quality on child adjustment. In M. E. Lamb, (Ed.), The role of the father in child development (3rd ed.; pp. 49-65). New York: John Wiley.

Doherty, W. J., Kouneski, E. F., \& Erickson, M. F. (1998). Responsible fathering: An overview and conceptual framework. Journal of Marriage and the Family, 60, 277-292.

Dollahite, D. C., \& Hawkins, A. J. (1998). A conceptual ethic of generative fathering. The Journal of Men's Studies, 7, 109-132.

Edelstein, R. S., Alexander, K. W., Shaver, P. R., Schaaf, J. M., Quas, J. A., Lovas, G. S., et al. (2004). Adult attachment style and parental responsiveness during a stressful event. Attachment and Human Development, 6, 31-52.

Erel, O., \& Burman, B. (1995). Interrelatedness of marital relations and parent-child relations: A meta-analytic review. Psychological Bulletin, 118, 108-132.

Erikson, E. H. (1964). Childhood and society (2nd ed.). New York: Norton.

Falk, R. F., \& Miller, N. B. (1996). A primer for soft modeling. Akron, OH: The University of Akron Press.

Fauber, R., Forehand, R., Thomas, A. M., \& Wierson, M. (1990). A mediational model of the impact of marital conflict on adolescent adjustment in intact and divorced families: The role of disrupted parenting. Child Development, 61, 1112-1123.

Fehr, B. (1993). How do I love thee? Let me consult my prototype. In S. Duck (Ed.), Understanding relationship processes series (Vol. 1). Individuals in relationships (pp. 87-120). Thousand Oaks, CA: Sage.

Fincham, F. D. (1998). Child development and marital relations. Child Development, 69, 543-574.

Fletcher, G. J. O., \& Fitness, J. (1993). Knowledge structures and explanations in intimate relationships. In S. Duck (Ed.), Understanding relationship processes series (Vol. 1). Individuals in relationships (pp. 121-143). Thousand Oaks, CA: Sage.

Fraley, R. C., \& Shaver, P. R. (2000). Adult romantic attachment: Theoretical developments, emerging controversies, and unanswered questions. Review of General Psychology, 4, 132-154.

Frosch, C. A., Mangelsdorf, S. C., \& McHale, J. L. (2000). Marital behavior and the security of preschooler-parent attachment relationships. Journal of Family Psychology, 14, 144-161.

Goldberg, W. A. (1990). Martial quality, parental personality, and spousal agreement about perceptions and expectations for children. Merrill-Palmer Quarterly, 36, 531-556.

Harold, G. T., Fincham, F. D., Osborne, L. N., \& Conger, R. D. (1997). Mom and dad are at it again: Adolescent perceptions of marital conflict and adolescent psychological distress. Developmental Psychology, 33, 333-350. 
Hawkins, A. J., Bradford, K. P., Palkovitz, R., Christiansen, S. L., Day, R. D., \& Call, V.R. A. (2002). The Inventory of Father Involvement: A pilot study of a new measure of father involvement. The Journal of Men's Studies, 10, 183-196.

Hawkins, A. J., Christiansen, S. L., Sargent, K. P., \& Hill, E. J. (1993). Rethinking fathers' involvement in child care. Journal of Family Issues, 14, 531-549.

Hawkins, A. J., \& Dollahite, D. C. (1997). Beyond the Role-Inadequacy Perspective of fathering. In A. J. Hawkins \& D. C. Dollahite (Eds.), Generative fathering: Beyond deficit perspectives (pp. 3-16). Thousand Oaks, CA: Sage.

Hawkins, A. J., \& Palkovitz, R. (1999). Beyond ticks and clicks: The need for more diverse and broader conceptualizations and measures of father involvement. The Journal of Men's Studies, 8, 11-32.

Heath, D. H. (1976). Competent fathers: Their personalities and marriages. Human Development, 19, 26-39.

Hetherington, E. M., Bridges, M., \& Insabella, G. M. (1998). What matters? What does not? Five perspectives on the association between marital transitions and children's adjustment. American Psychologist, 53, 167-184.

Hetherington, E. M., \& Parke, R. D. (1993). Child psychology: A contemporary viewpoint. New York: McGraw-Hill.

Holman, T. B., Busby, D. M., Doxey, C., Klein, D. M., \& Loyer-Carlson, V. (1997). Relationship Evaluation (RELATE). Marriage Study Consortium. Provo, UT.

Howes, P., \& Markman, H. J. (1989). Marital quality and child functioning: A longitudinal investigation. Child Development, 60, 1044-1051.

Julian, T. W., \& Knapp, T. R. (1995). The National Survey of Families and Households: A rich data base for nursing research. Research in Nursing and Health, 18, 173177.

Kotre, J. (1984). Outliving the self: Generativity and the interpretation of lives. Baltimore: The Johns Hopkins University Press.

Krishnakumar, A., \& Buehler, C. (2000). Interpersonal conflict and parenting behaviors: A meta-analytic review. Family Relations, 49, 25-44.

Lamb, M. E., Pleck, J. H., Charnov, E. L., \& Levine, J. A. (1985). Paternal behavior in humans. American Zoologist, 25, 883-894.

Lamb, M. E., Pleck, J. H., Charnov, E. L., \& Levine, J. A. (1987). A biosocial perspective on paternal behavior and involvement. In J. B. Lancaster, J. Altman, A. Rossi, \& L. R. Sherrod (Eds.), Parenting across the lifespan: Biosocial perspectives (pp. 11-42). New York: Academic.

Lerner, R. M. (1986). Concepts and theories of human development. New York: Random House.

Marsiglio, W., Day, R. D., \& Lamb, M. E. (2000). Exploring fatherhood diversity: Implications for conceptualizing father involvement. In H. E. Peters, G. W. Peterson, S. K. Steinmetz, \& R. D. Day (Eds.), Fatherhood: Research, interventions, and policies (pp. 269-293). New York: The Haworth Press. 
Maurer, T. W, Pleck, J. H., \& Rane, T. R (2001). Parental identity and reflected-appraisals: Measurement and gender dynamics. Journal of Marriage and the Family, 63, 309-321.

McAdams, D. P., \& de St. Aubin, E. (1992). A theory of generativity and its assessment through self-report, behavioral acts, and narrative themes in autobiography. Journal of Personality and Social Psychology, 62, 1003-1015.

McBride, B. A., \& Rane, T. R (1998). Parenting alliance as a predictor of father involvement: An exploratory study. Family Relations, 47, 229-235.

The Morehouse Research Institute \& The Institute for American Values. (1999). Turning the corner on father absence in Black America. Atlanta, GA: The Morehouse Research Institute.

Nock, S. L. (1998). Marriage in men's lives. New York: Oxford University Press.

Noller, P. (1996). What is this thing called love? Defining the love that supports marriage and family. Personal Relationships, 3, 97-115.

Palkovitz, R. (1997). Reconstructing “involvement:” Expanding conceptualizations of men's caring in contemporary families. In A. J. Hawkins \& D. C. Dollahite (Eds.), Generative fathering: Beyond deficit perspectives (pp. 200-216). Thousand Oaks, CA: Sage.

Pill, C. J. (1990). Stepfamilies: Redefining the family. Family Relations, 39, 186-193.

Pleck, J. H. (1997). Paternal involvement: Levels, sources, and consequences. In M. E. Lamb (Ed.), The role of the father in child development, (3rd ed., pp. 66-103). New York: John Wiley \& Sons.

Pleck, J. H., \& Stueve, J.L. (2001). Time and paternal involvement. In K. Daly (Ed.), Minding the time in family experience: Emerging perspectives and issues. Contemporary perspectives on family research, Vol.3. St. Louis, MO: Elsevier Science \& Technology Books.

Rholes, W. S., Simpson, J. A., Blakely, B. S., Lanigan, L., \& Allen, E. A. (1997). Adult attachment styles, the desire to have children, and working models of parenthood. Journal of Personality, 65, 357-385

Schumm, W. R. (1986). Kansas Parental Satisfaction Scale. Journal of Marriage and the Family, 48, 381-387.

Shek, D. T. L. (1998). Linkage between marital quality and parent-child relationship: A longitudinal study in the Chinese culture. Journal of Family Issues, 19, 687704.

Snarey, J. (1993). How fathers care for the next generation:A four decade study. Cambridge, MA: Harvard University Press.

Snarey, J. (1997). Forward: The next generation of work on fathering. In A. J. Hawkins \& D. C. Dollahite (Eds.), Generative fathering: Beyond deficit perspectives (pp. ixxii). Thousand Oaks, CA: Sage.

Stanley, S. M., Whitton, S. W., \& Markman, H. J. (2004). Maybe I do: Interpersonal commitment and premarital or nonmarital cohabitation. Journal of Family Issues, 25, 496-519.

Sternberg, R. J. (1986). A triangular theory of love. Psychological Review, 93, 119-135. 
Sweet, J., Bumpass, L., \& Call, V. (1992). National Survey of Families and Households 1988. Madison, WI: Center for Demography and Ecology, University of Wisconsin.

Teachman, J. D., Tedrow, L. M., \& Crowder, K. D. (2000). The changing demography of America's families. Journal of Marriage and the Family, 62, 1234-1246.

White, L. (1999). Contagion in family affection: Mothers, fathers, and young adult children. Journal of Marriage and the Family, 61, 284-294.

Whyte, M. K. (1990). Dating, mating, and marriage. New York: Aldine de Gruyter.

Wood, B. L., Klebba, K. B., \& Miller, B. D. (2000). Evolving the biobehavioral family model: the fit of attachment. Family Process, 39, 319-344. 